\title{
Photometric Determination of Rhenium with Potassium Hexacyanoferrate(II) in Presence of Thiocyanate
}

\author{
Anu WAHI and L. R. KAKKaR ${ }^{\dagger}$ \\ Department of Chemistry, Kurukshetra University, Kurukshetra-132119, Haryana State, India
} Keywords Rhenium, spectrophotometric determination, ascorbic acid, potassium hexacyanoferrate(II), thiocyanate,
isopentyl alcohol

Potassium hexacyanoferrate(II) ${ }^{1}$ has earlier been used as a complexing agent for rhenium in the presence of tin(II) chloride, forming a colored complex in hydrochloric acid solution. The method utilizing this reaction for the determination of rhenium, however, could not gain much importance for want of sensitivity; interferences from vanadium, tungsten, chromium, copper and platinum metals in particular also caused trouble. The intensity of the colored complex formed between lower valent rhenium, obtained on reduction with ascorbic acid, and potassium hexacyanoferrate(II) increases considerably in presence of thiocyanate with relatively higher tolerance limits of other ions on extraction into isopentyl alcohol. Therefore, the system presented below makes use of this fact to work out a determination procedure for rhenium. This involves the formation of a mixed ligand complex by the metal ion with hexacyanoferrate(II) and thiocyanate using ascorbic acid as the reductant.

\section{Experimental}

\section{Reagents}

Rhenium solution, $1 \mathrm{mg} \mathrm{m}^{-1}$. A stock solution of rhenium is prepared by dissolving $0.1554 \mathrm{~g}$ of potassium perrhenate, $\mathrm{KReO}_{4}$ ("Specpure" Johnson Matthey \& Co.) in distilled water containing a few drops of $5 \mathrm{M} \mathrm{HCl}$ which is finally diluted to $100 \mathrm{ml}$. Lower concentrations of rhenium at $\mu \mathrm{g} \mathrm{ml}^{-1}$ level are obtained by suitable dilutions therefrom.

Potassium thiocyanate. $\quad 20 \%$.

Potassium hexacyanoferrate(II). A A 2\% solution of the reagent is prepared in distilled water afresh daily.

Ascorbic acid (Loba Chemie) is used as solid. Isopentyl alcohol (Qualigens) is distilled and the fraction distilling between $128-132^{\circ} \mathrm{C}$ is collected for use. Solutions of other metal ions $\left(\mathrm{mg} \mathrm{ml}^{-1}\right)$ are prepared by dissolving their commonly available salts of chemically

\footnotetext{
To whom correspondence should be addressed.
}

pure grade in distilled water or diluted acid solutions.

For absorbance measurements, a UV-visible 140-02 spectrophotometer (Shimadzu, Japan) is used.

\section{Synthetic and flue dust samples}

Synthetic samples are prepared by mixing $\mu \mathrm{g}$ amounts of rhenium with suitable amounts of other, metal ions, as shown in Table 2.

A reverberatory flue dust sample from copper manufacture, containing no rhenium, is mixed with a solution of known content of rhenium and dried in an oven. After complete fusion of the sample with sodium peroxide in a nickel crucible, the leach is neutralized with conc. $\mathrm{H}_{2} \mathrm{SO}_{4}$ and made slightly alkaline with $\mathrm{NaOH}$. It is boiled and the hydroxide precipitate is filtered and washed well with distilled water. The filtrate along with the washings is adjusted to the experimental conditions described below in the procedure for the determination of rhenium.

\section{Procedure}

To an aliquot containing $100 \mu \mathrm{gRe}$ and/or other ions in a $25 \mathrm{ml}$ beaker, add $500 \mathrm{mg}$ ascorbic acid, $2.5 \mathrm{ml} 10 \mathrm{M}$ $\mathrm{HCl}, 4 \mathrm{ml} \mathrm{20 \%} \mathrm{KSCN}, 2 \mathrm{ml} 2 \%$ potassium hexacyanoferrate(II) and dilute it to $10 \mathrm{ml}$. Gently mix the contents, heat gradually to $70^{\circ} \mathrm{C}$ and allow it to stand for $10 \mathrm{~min}$ at room temperature. The dark orange-yellow metal complex so formed is transferred to a $100 \mathrm{ml}$ separatory funnel, diluted to $20 \mathrm{ml}$ with water and extracted once with an equal volume of isopentyl alcohol for $1 \mathrm{~min}$. The organic layer is filtered through a Whatman filter paper No. 41 to remove any suspended droplets of water, into a $25 \mathrm{ml}$ volumetric flask, which is made up to the mark with the pure solvent. The absorbance of the complex is measured at $440 \mathrm{~nm}$ using a blank extract as the reference solution. Rhenium is determined from the calibration curve constructed from the data obtained in a similar manner by taking different amounts of the metal ion in each set and measuring their corresponding absorbance values. 


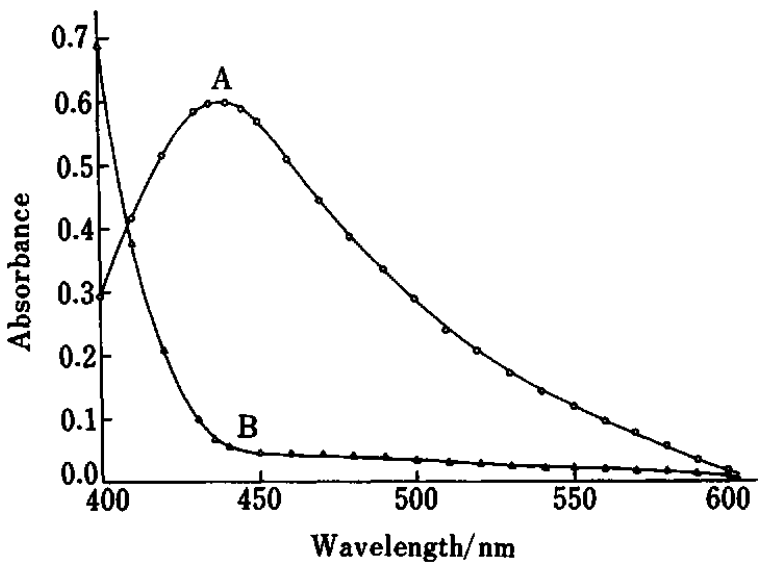

Fig. 1 Absorption spectrum of Re-complex in isopentyl alcohol. Curve A: $4 \mu \mathrm{gRe} / \mathrm{ml}$ measured against reagent blank; B: reagent blank measured against isopentyl alcohol.

\section{Results and Discussion}

Perrhenate ion, $\mathrm{ReO}_{4}^{-}$, in the presence of thiocyanate, forms a dark orange-yellow complex with potassium hexacyanoferrate(II) on reduction with ascorbic acid in hydrochloric acid solution at a temperature of $c a .70^{\circ} \mathrm{C}$. The absorption spectrum of the metal complex indicates that $\lambda_{\max }$ lies at $440 \mathrm{~nm}$, where the absorbance of the reagent blank is minimal (Fig. 1).

At $2 \mathrm{M}\left(\mathrm{mol} \mathrm{dm}^{-3}\right)$ of hydrogen ion, the absorbance of the metal complex in different acid, solutions decreases in the order $-\mathrm{HCl}>\mathrm{H}_{2} \mathrm{SO}_{4}>\mathrm{H}_{3} \mathrm{PO}_{4}>\mathrm{CH}_{3} \mathrm{COOH}$, if other aqueous conditions are kept the same in each case (i.e. $\mathrm{Re}=100 \mu \mathrm{g}$, ascorbic asid $=500 \mathrm{mg}, \mathrm{KSCN}=4 \mathrm{ml}$, potassium hexacyanoferrate(II) $=2 \mathrm{ml}$, temperature $c a \cdot 70^{\circ} \mathrm{C}$, color development time $=10 \mathrm{~min}$ ). Hence, hydrochloric acid provides a suitable medium for the system.

Various operative parameters affecting the absorbance of the metal complex, namely temperature, color development time, $\mathrm{HCl}$ concentration, ascorbic acid, thiocyanate and potassium hexacyanoferrate(II) are shown in Table 1. From these studies, we concluded that for $100 \mu \mathrm{g}$ Re: $2.3-2.8 \mathrm{M} \mathrm{HCl}, 0.25-1.50 \mathrm{~g}$ of ascorbic acid, $3.8-4.2 \mathrm{ml} \mathrm{KSCN}, 1.8-4.0 \mathrm{ml}$ potassium hexacyanoferrate(II) in $10 \mathrm{ml}$ volume, heating to $67-$ $73^{\circ} \mathrm{C}, 8-15$ min color development time, dilution to $20 \mathrm{ml}$ and shaking once for $1 \mathrm{~min}$ with an equal volume of isopentyl alcohol, are the optinum conditions for the quantitative transfer of the metal complex to the solvent phase. Its absorption is measured at $440 \mathrm{~nm}$ after making up the volume to $25 \mathrm{ml}$ as described in the procedure.

Under the conditions chosen for the procedure, the extraction of the metal complex has also been tried in various solvents. The absorbance is found to decrease in the order-isopentyl alcohol $>$ isopentyl acetate $>$ ethyl acetate $>$ isopentyl alcohol-chloroform $(1: 3)>$ isobutyl methyl ketone>ethyl methyl ketone. It is almost negligible in case of pure chloroform and benzene. Hence, isopentyl alcohol is considered to be a suitable extracting solvent for the metal complex.

\section{Effect of diverse ions}

Sulfate $(200 \mathrm{mg})$, acetate $(100 \mathrm{mg})$, citrate $(50 \mathrm{mg})$, tartrate $(50 \mathrm{mg})$, phosphate $(100 \mathrm{mg})$ and EDTA $(50 \mathrm{mg})$ do not affect the absorbance of the metal complex; but chloride $(100 \mathrm{mg})$ and fluoride $(50 \mathrm{mg})$ increase it slightly. The presence of oxalate $(100 \mathrm{mg})$, nitrate (100 mg), thiourea, $50 \mathrm{mg}$, and $\mathrm{H}_{2} \mathrm{O}_{2}, 1 \mathrm{ml} 30 \% \mathrm{w} / \mathrm{v}$, lowers the absorbance. The figure shown in brackets indicates the amount of the sodium salt of the anion

Table 1 Effect of various parameters on the absorbance of the Re-complex

\begin{tabular}{|c|c|c|c|c|c|c|c|c|c|c|c|c|}
\hline Temperature ${ }^{\mathrm{a}}\left({ }^{\circ} \mathrm{C}\right)$ & 40 & 45 & 50 & 55 & 60 & 65 & 67 & 70 & 73 & 75 & 80 & 85 \\
\hline Absorbance & 0.025 & 0.040 & 0.115 & 0.210 & 0.590 & 0.610 & 0.620 & 0.620 & 0.620 & 0.615 & 0.590 & 0.575 \\
\hline $\begin{array}{l}\text { Color development } \\
\text { time }^{\text {b }} \text { (min) }\end{array}$ & 0 & 5 & 8 & 10 & 15 & & & & & & & \\
\hline Absorbance & 0.460 & 0.605 & 0.620 & 0.620 & 0.620 & & & & & & & \\
\hline Ascorbic acid ${ }^{\mathfrak{c}}(\mathrm{g})$ & 0.00 & 0.05 & 0.10 & 0.20 & 0.25 & 0.50 & 1.00 & 1.50 & & & & \\
\hline Absorbance & 0.510 & 0.565 & 0.590 & 0.610 & 0.620 & 0.620 & 0.620 & 0.620 & & & & \\
\hline $\mathrm{HCl}^{\mathrm{d}}[\mathbf{M}]$ & 0.0 & 0.5 & 1.0 & 1.5 & 2.0 & 2.3 & 2.5 & 2.8 & 3.0 & 3.5 & 4.0 & \\
\hline Absorbance & 0.011 & 0.030 & 0.125 & 0.585 & 0.610 & 0.620 & 0.620 & 0.620 & 0.607 & 0.580 & 0.567 & \\
\hline $\mathrm{KSCN}^{\mathrm{e}}(\mathrm{ml})$ & 0.0 & 0.5 & 1.0 & 2.0 & 3.0 & 3.5 & 3.8 & 4.0 & 4.2 & 4.5 & 5.0 & 6.0 \\
\hline Absorbance & 0.010 & 0.210 & 0.364 & 0.575 & 0.589 & 0.615 & 0.620 & 0.620 & 0.620 & 0.610 & 0.592 & 0.565 \\
\hline $\begin{array}{l}\text { Potassium } \\
\quad \text { hexacyanoferrate }(\mathrm{II})^{\mathrm{f}}(\mathrm{ml})\end{array}$ & 0.0 & 0.5 & 1.0 & 1.5 & 1.8 & 2.0 & 2.5 & 3.0 & 4.0 & & & \\
\hline Absorbance & 0.600 & 0.610 & 0.620 & 0.635 & 0.640 & 0.640 & 0.640 & 0.640 & 0.640 & & & \\
\hline
\end{tabular}

[Conditions] a. $\mathrm{Re}=100 \mu \mathrm{g}$, ascorbic acid $=500 \mathrm{mg}, \mathrm{HCl}=2.5 \mathrm{M}, \mathrm{KSCN}=4 \mathrm{ml}$, potassium hexacyanoferrate(II) $=1 \mathrm{ml}$, color development time $=10 \mathrm{~min}$, temperature $=$ variable. b. Temperature $=70^{\circ} \mathrm{C}$, other conditions being the same as in (a) except for variation in color development time. c. Color development time $=10 \mathrm{~min}$, other conditions being the same as in (b) except for variation in the amount of ascorbic acid. d. Ascorbic acid $=500 \mathrm{mg}$, other conditions being the same as in (c) except for variation in acid concentration. e. $\mathrm{HCl}=2.5 \mathrm{M}$, other conditions being the same as in (d) except for variation in $\mathrm{KSCN}$ concentration. f. $\mathrm{KSCN}=4 \mathrm{ml}$, other conditions being the same as in (e) except for variation in potassium hexacyanoferrate(II) concentration. 


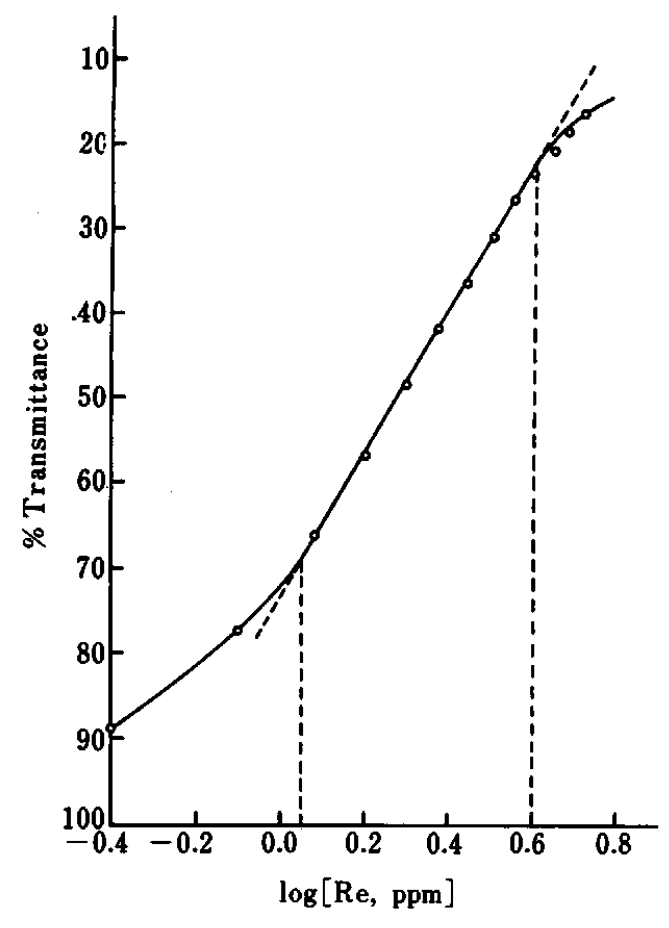

Fig. 2 Ringbom plot of Re-complex at $440 \mathrm{~nm}$.

added initially to the aqueous solution.

The cations which do not show any absorption under conditions of the procedure include $\mathrm{Ca}^{\mathrm{II}}, \mathrm{Ba}^{\mathrm{II}}, \mathrm{Mg}^{\mathrm{II}}, \mathrm{Hg}^{\mathrm{II}}$, $\mathrm{Bi}^{\mathrm{III}}, \mathrm{Ce}^{\mathrm{IV}}, \mathrm{As}^{\mathrm{v}}, 5 \mathrm{mg} / 20 \mathrm{ml} ; \mathrm{Ag}^{\mathrm{I}}, \mathrm{Mn}^{\mathrm{II}}, \mathrm{Zn}^{\mathrm{II}}, \mathrm{Pb}^{\mathrm{II}}, \mathrm{Sb}^{\mathrm{III}}$, $\mathrm{Al}^{\mathrm{III}}, 2.5 \mathrm{mg} / 25 \mathrm{ml} ; \mathrm{Cu}^{\mathrm{II}}, \mathrm{Ni}^{\mathrm{II}}, \mathrm{Se}^{\mathrm{IV}}, \mathrm{Nb}^{\mathrm{v}}, \mathrm{Ta}^{\mathrm{v}}, 2 \mathrm{mg} /$ $20 \mathrm{ml} ; \mathrm{Co}^{\mathrm{II}}, \mathrm{Fe}^{\mathrm{II}}, \mathrm{Fe}^{\mathrm{III}}, \mathrm{Cr}^{\mathrm{III}}, \mathrm{Zr}^{\mathrm{IV}}, \mathrm{Cr}^{\mathrm{vI}}, \mathrm{W}^{\mathrm{vI}}, 1 \mathrm{mg} / 20 \mathrm{ml}$; $\mathrm{Au}^{\mathrm{III}}, \mathrm{V}^{\mathrm{v}}, 0.5 \mathrm{mg} / 20 \mathrm{ml} ; \mathrm{Pd}^{\mathrm{II}}, \mathrm{Ru}^{\mathrm{IIII}}, \mathrm{Ir}^{\mathrm{III}}, \mathrm{Pt}^{\mathrm{IV}}, \mathrm{Os}^{\mathrm{vIII}}$, $0.25 \mathrm{mg} / 20 \mathrm{ml}$. Mo, $0.1 \mathrm{mg} / 20 \mathrm{ml}$, interferes.

Stability, reproducibility, Beer's law obedience and Sandell's sensitivity of the complex

The metal complex is quite stable; the absorbance remains unchanged even after $2 \mathrm{~h}$. The results obtained are highly reproducible, with a standard deviation of 0.001 . Beer's law is obeyed in the range of $0-4$ $\mu \mathrm{gRe} \mathrm{ml}^{-1}$. The optimum concentration range that can be measured accurately, as evaluated from the Ringbom plot, is $1.12-3.98 \mathrm{ppm}$ of $\operatorname{Re}$ (Fig. 2). Molar absorptivity, specific absorptivity and Sandell's sensitivity of the complex are $2.98 \times 10^{4} \mathrm{dm}^{3} \mathrm{~mol}^{-1} \mathrm{~cm}^{-1}, 1.60 \times 10^{-1} \mathrm{ml} \mathrm{g}^{-1}$ $\mathrm{cm}^{-1}$ and $0.0062 \mu \mathrm{gRe} \mathrm{cm}^{-2}$, respectively.

\section{Stoichiometry of the complex}

The ratio of rhenium, thiocyanate and potassium hexacyanoferrate(II) in the extracted species is determined by job's method of continuous variations ${ }^{2}$ as modified by Vosburgh and Cooper ${ }^{3}$ for the two-phase system.

Re:thiocyanate. $\quad x \mathrm{ml}$ of $1.613 \times 10^{-3} \mathrm{M}$ solution of $\mathrm{KReO}_{4}$ and $(5-x) \mathrm{ml}$ of equimolar solution of $\mathrm{KSCN}$ are mixed and extraction is performed under conditions of the procedure. The absorbance of the metal complex is measured at 400 and $440 \mathrm{~nm}$. The graph plotted between different mole fractions of $\mathrm{Re}$ and their

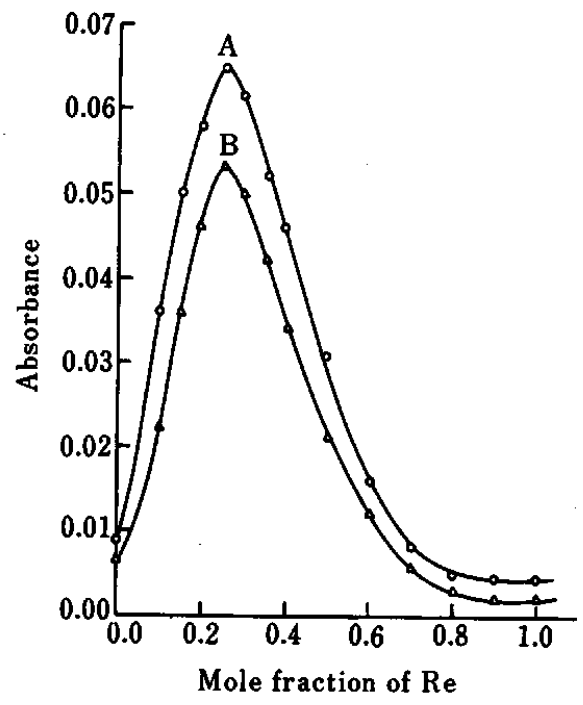

Fig. 3 Continuous variation of rhenium and thiocyanate. Concentration of $\mathrm{KReO}_{4}, 1.613 \times 10^{-3} \mathrm{M} ; \mathrm{KSCN}, 1.613 \times$ $10^{-3} \mathrm{M}$. Solvent, isopentyl alcohol. Curve A, at $400 \mathrm{~nm}$; B, $440 \mathrm{~nm}$.

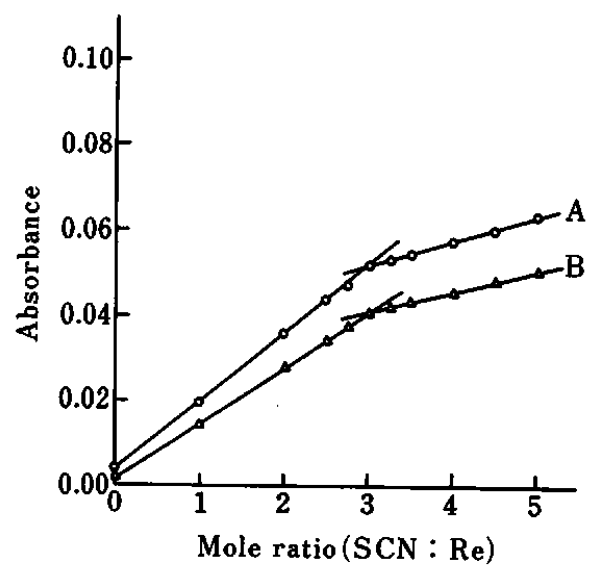

Fig. 4 Mole ratio method. Concentration of $\mathrm{KReO}_{4}$, $1.613 \times 10^{-3} \mathrm{M}$; KSCN, $1.613 \times 10^{-3} \mathrm{M}$. Re for each operation, $1 \mathrm{ml}$ of $1.613 \times 10^{-3} \mathrm{M}$. Solvent, isopentyl alcohol. Curve A, at $400 \mathrm{~nm} ; \mathrm{B}, 440 \mathrm{~nm}$.

corresponding absorbance values indicates that $\mathrm{Re}$ and thiocyanate are present in the ratio of $1: 3$ (Fig. 3).

This fact is further supported by the mole ratio method. ${ }^{4}$ Here, the volume of rhenium solution is kept constant $\left(1 \mathrm{ml}\right.$ of $\left.1.613 \times 10^{-3} \mathrm{M}\right)$ and the content of equimolar solution of thiocyanate is varied from 0 to $5 \mathrm{ml}$. After this procedure, the absorbances are measured and a graph is plotted between different mole ratios and their corresponding absorbance values, as shown in Fig. 4. This plot also gives the same ratio.

Re:potassium hexacyanoferrate(II). The ratio of rhenium to potassium hexacyanoferrate(II) in the metal complex is found to be $1: 1$ by Job's method, using equimolar solutions $\left(2.69 \times 10^{-4} \mathrm{M}\right)$ of both the variables. While maintaining other conditions as per procedure, we performed the extraction and plotted the graph from the 


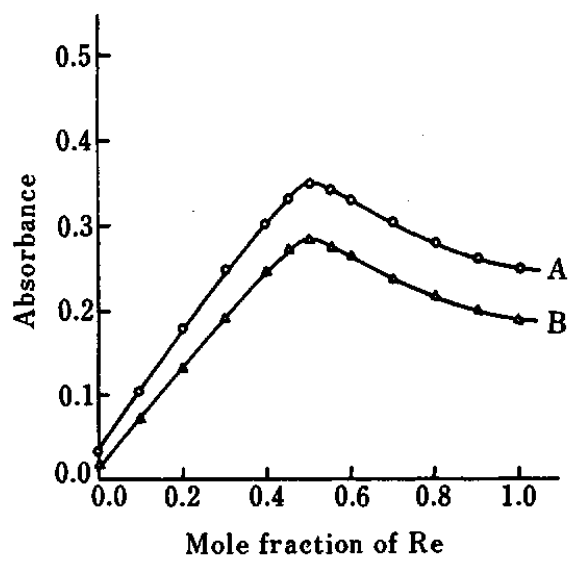

Fig. 5 Continuous variation of rhenium and potassium hexacyanoferrate(II). Concentration of $\mathrm{KReO}_{4}, 2.69 \times 10^{-4}$ M; potassium hexacyanoferrate(II), $2.69 \times 10^{-4} \mathrm{M}$. Solvent, isopentyl alcohol. Curve $A$, at $400 \mathrm{~nm} ; B, 440 \mathrm{~nm}$.

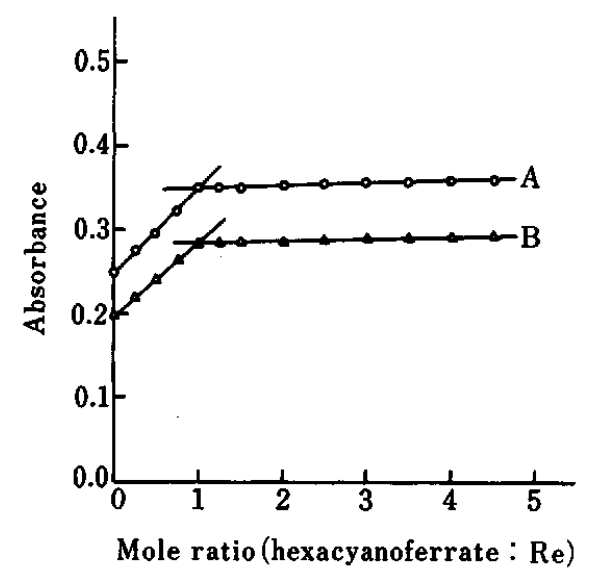

Fig. 6 Mole ratio method. Concentration of $\mathrm{KReO}_{4}, 2.69 \times$ $10^{-4} \mathrm{M}$; Potassium hexacyanoferrate(II), $2.69 \times 10^{-4} \mathrm{M}$. Re for each operation, $1 \mathrm{ml}$ of $2.69 \times 10^{-4} \mathrm{M}$. Solvent, isopentyl alcohol. Curve A, at $400 \mathrm{~nm} ; \mathrm{B}, 440 \mathrm{~nm}$. data obtained (Fig. 5). The same result is confirmed by the mole ratio method (Fig. 6).

The above studies allow us to conclude that Re, potassium hexacyanoferrate(II) and thiocyanate are present in the ratio of $1: 1: 3$ in the extracted species.

In conclusion, the proposed method for the trace determination of rhenium is quite sensitive and free from the interference of 31 analytically important elements, including $\mathrm{Pt}$-metals while $\mathrm{Mo}^{\mathrm{vI}}$ interferes. The validity of the method was tested by satisfactory analysis of a number of samples. The method is highly reproducible and compares favorably with the existing methods ${ }^{5-9}$ of rhenium determination.

Our sincere thanks are due to the Chairman, Department of Chemistry, Kurukshetra University, Kurukshetra, for providing laboratory facilities and to the Department of Atomic Energy, Bombay, for financial assistance to one of us (AW).

\section{References}

1. V. M. Tarayan and S. V. Vartanyan, Izv. Akad. Nauk. Arm. SSR, Khim. Nauk., 20, 179.(1967).

2. P. Job, Ann. Chim., 9, 113 (1928).

3. W. C. Vosburgh and G. R. Cooper, J. Am. Chem. Soc., 63, 437 (1941).

4. J. H. Yoe and A. L. Jones, Ind. Eng. Chem. Anal. Ed., 16, 111 (1944).

5. A. N. Nayak, S. Manjappa, P. G. Ramappa and H. S. Yathirajan, Fresenius' Z. Anal. Chem., 309, 396 (1981).

6. S. P. Bag and C. R. Chanda, J. Indian Chem. Soc., 59, 688 (1982).

7. S. Gangopadhyay, P. K. Gangopadhyay and S. C. Shome, Anal. Chim. Acta, 83, 409 (1976).

8. S. P. Bag and C. R. Chanda, J. Indian Chem. Soc., 58, 29 (1981).

9. A. Wahi and L. R. Kakkar, Anal. Sci., 9, 409 (1993).

(Received June 25, 1993)

(Accepted November 5, 1993) 